\title{
Correction to: An online international comparison of thresholds for triggering a negative response to the "Surprise Question": a study protocol
}

Nicola White ${ }^{1 *}$, Linda Oostendorp ${ }^{1}$, Victoria Vickerstaff ${ }^{1}$, Christina Gerlach², Yvonne Engels ${ }^{3}$, Maud Maessen ${ }^{4}$, Christopher Tomlinson ${ }^{5}$, Johan Wens ${ }^{6}$, Bert Leysen ${ }^{6}$, Guido Biasco ${ }^{7}$, Sofia Zambrano ${ }^{4}$, Steffen Eychmüller ${ }^{4}$, Christina Avgerinou', Rabih Chattat $^{8}$, Giovanni Ottoboni ${ }^{8}$, Carel Veldhoven ${ }^{3}$ and Patrick Stone ${ }^{1}$

\section{Correction to: BMC Palliat Care}

https://doi.org/10.1186/s12904-019-0413-X

Following publication of the original article [1], an error in reference 18 was reported.

Reference 18 did not include all authors. The correct reference should read: Romo RD, Lynn J. The utility and value of the "surprise question" for patients with serious illness. Can Med Assoc J. 2017;189(33):E1072-3.

\section{Author details}

${ }^{1}$ University College London, London, UK. ${ }^{2}$ University of Mainz, Mainz,

Germany. ${ }^{3}$ Radboud University Medical Centre, Nijmegen, The Netherlands.

${ }^{4}$ University Hospital of Bern, Bern, Switzerland. 5 Imperial College London,

London, UK. ${ }^{6}$ University of Antwerp, Antwerp, Belgium. ${ }^{7}$ University of

Bologna \& Academy of the Sciences of Palliative Medicine, Bologna, Italy.

${ }^{8}$ University of Bologna, Bologna, Italy.

Published online: 27 January 2020

\section{Reference}

1. White N, Oostendorp L, Vickerstaff V, Gerlach C, Engels Y, Maessen M, Tomlinson C, Wens J, Leysen B, Biasco G, Zambrano S, Eychmüller S, Avgerinou C, Chattat R, Ottoboni G, Veldhoven C, Stone P. An online international comparison of thresholds for triggering a negative response to the "Surprise Question": a study protocol. BMC Palliat Care. 2019;18:36.

Full list of author information is available at the end of the article 